\title{
Cisatracurium Besylate
}

National Cancer Institute

\section{Source}

National Cancer Institute. Cisatracurium Besylate. NCI Thesaurus. Code C47451.

A non-depolarizing skeletal muscle relaxant of the benzylisoquinolinium class.

Cisatracurium besylate acts as a competitive acetylcholine antagonist that binds to nicotinic receptors at the neuromuscular junction. Compared to other neuromuscular blocking agents, it is intermediate in its onset and duration of action. Cisatracurium besylate is used to maintain neuromuscular relaxation during major surgical procedures, primarily to facilitate endotracheal intubation. Cisatracurium besylate can cause bronchospasms, hypotension, and bradycardia. 